\title{
Effect of Ti-Al cathode composition on plasma generation and plasma transport in direct current vacuum arc
}

\author{
Igor Zhirkov, Anders Eriksson, Andrejs Petruhins, Martin Dahlqvist, Arni Sigurdur Ingason
} and Johanna Rosén

\section{Linköping University Post Print}

\section{Tweet}

N.B.: When citing this work, cite the original article.

Original Publication:

Igor Zhirkov, Anders Eriksson, Andrejs Petruhins, Martin Dahlqvist, Arni Sigurdur Ingason and Johanna Rosén, Effect of Ti-Al cathode composition on plasma generation and plasma transport in direct current vacuum arc, 2014, Journal of Applied Physics, (115), 12, 123301. http://dx.doi.org/10.1063/1.4869199

Copyright: American Institute of Physics (AIP) http://www.aip.org/

Postprint available at: Linköping University Electronic Press

http://urn.kb.se/resolve?urn=urn:nbn:se:liu:diva-106517 


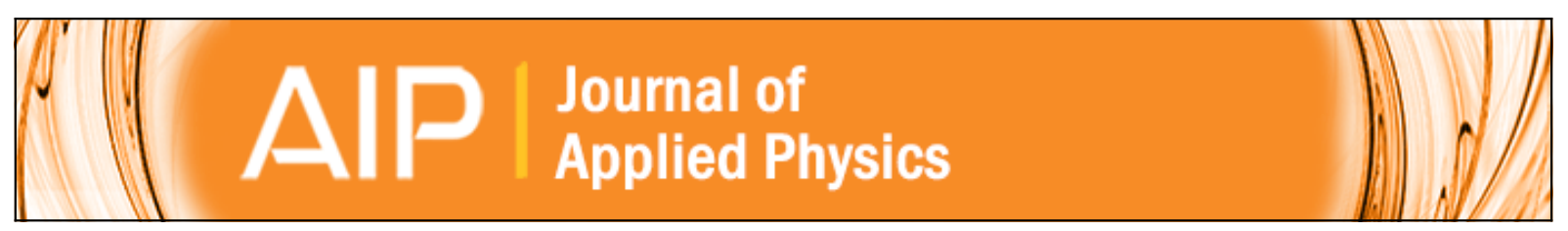

Effect of Ti-Al cathode composition on plasma generation and plasma transport in direct current vacuum arc

I. Zhirkov, A. O. Eriksson, A. Petruhins, M. Dahlqvist, A. S. Ingason, and J. Rosen

Citation: Journal of Applied Physics 115, 123301 (2014); doi: 10.1063/1.4869199

View online: http://dx.doi.org/10.1063/1.4869199

View Table of Contents: http://scitation.aip.org/content/aip/journal/jap/115/12?ver=pdfcov

Published by the AIP Publishing

\section{Articles you may be interested in}

The effect of cathode geometry on barium transport in hollow cathode plasmas

J. Appl. Phys. 115, 183301 (2014); 10.1063/1.4873168

Ion velocities in direct current arc plasma generated from compound cathodes

J. Appl. Phys. 114, 213302 (2013); 10.1063/1.4841135

Characterization of plasma chemistry and ion energy in cathodic arc plasma from Ti-Si cathodes of different compositions

J. Appl. Phys. 113, 163304 (2013); 10.1063/1.4802433

Generation of multicomponent ion beams by a vacuum arc ion source with compound cathodea)

Rev. Sci. Instrum. 81, $02 A 501$ (2010); 10.1063/1.3257703

Charge state dependence of cathodic vacuum arc ion energy and velocity distributions

Appl. Phys. Lett. 89, 141502 (2006); 10.1063/1.2361197

AAP Re-register for Table of Content Alerts 


\title{
Effect of Ti-Al cathode composition on plasma generation and plasma transport in direct current vacuum arc
}

\author{
I. Zhirkov, ${ }^{1, a)}$ A. O. Eriksson, ${ }^{1,2}$ A. Petruhins, ${ }^{1}$ M. Dahlqvist, ${ }^{1}$ A. S. Ingason, ${ }^{1}$ and J. Rosen ${ }^{1}$ \\ ${ }^{1}$ Thin Film Physics Division, Department of Physics, Chemistry and Biology (IFM), Linköping University, \\ SE-581 83 Linköping, Sweden \\ ${ }^{2}$ Oerlikon Balzers Coating AG, Iramali 18, 9496 Balzers, Liechtenstein
}

(Received 23 December 2013; accepted 10 March 2014; published online 25 March 2014)

\begin{abstract}
DC arc plasma from $\mathrm{Ti}, \mathrm{Al}$, and $\mathrm{Ti}_{1-\mathrm{x}} \mathrm{Al}_{\mathrm{x}}(\mathrm{x}=0.16,0.25,0.50$, and 0.70$)$ compound cathodes was characterized with respect to plasma chemistry and charge-state-resolved ion energy. Scanning electron microscopy, X-ray diffraction, and Energy-dispersive X-ray spectroscopy of the deposited films and the cathode surfaces were used for exploring the correlation between cathode-, plasma-, and film composition. Experimental work was performed at a base pressure of $10^{-6}$ Torr, to exclude plasma-gas interaction. The plasma ion composition showed a reduction of $\mathrm{Al}$ of approximately 5 at. \% compared to the cathode composition, while deposited films were in accordance with the cathode stoichiometry. This may be explained by presence of neutrals in the plasma/vapour phase. The average ion charge states $(\mathrm{Ti}=2.2, \mathrm{Al}=1.65)$ were consistent with reference data for elemental cathodes, and approximately independent on the cathode composition. On the contrary, the width of the ion energy distributions (IEDs) were drastically reduced when comparing the elemental $\mathrm{Ti}$ and $\mathrm{Al}$ cathodes with $\mathrm{Ti}_{0.5} \mathrm{Al}_{0.5}$, going from $\sim 150$ and $\sim 175 \mathrm{eV}$ to $\sim 100$ and $\sim 75 \mathrm{eV}$ for $\mathrm{Ti}$ and $\mathrm{Al}$ ions, respectively. This may be explained by a reduction in electron temperature, commonly associated with the high energy tail of the IED. The average Ti and $\mathrm{Al}$ ion energies ranged between $\sim 50$ and $\sim 61 \mathrm{eV}$, and $\sim 30$ and $\sim 50 \mathrm{eV}$, respectively, for different cathode compositions. The attained energy trends were explained by the velocity rule for compound cathodes, which states that the most likely velocities of ions of different mass are equal. Hence, compared to elemental cathodes, the faster Al ions will be decelerated, and the slower Ti ions will be accelerated when originating from compound cathodes. The intensity of the macroparticle generation and thickness of the deposited films were also found to be dependent on the cathode composition. The presented results may be of importance for choice of cathodes for thin film depositions involving compound cathodes. (C) 2014 AIP Publishing LLC. [http://dx.doi.org/10.1063/1.4869199]
\end{abstract}

\section{INTRODUCTION}

Metastable $(\mathrm{Ti}, \mathrm{Al}) \mathrm{N}$ coatings are widely used as wearresistance and anti-corrosion material due to its superior mechanical properties and oxidation resistance. ${ }^{1-4}$ For instance, $(\mathrm{Ti}, \mathrm{Al}) \mathrm{N}$ coating raises the oxidation threshold temperature up to $800^{\circ} \mathrm{C}$ compared to $500^{\circ} \mathrm{C}$ of TiN coating. ${ }^{5,6}$ Industrial PVD synthesis of $(\mathrm{Ti}, \mathrm{Al}) \mathrm{N}$ by operating of cathodic arc in nitrogen atmosphere is an established technique, ${ }^{7}$ where a common approach is to mix $\mathrm{Ti}$ and $\mathrm{Al}$ in a compound cathode from which plasma is generated. ${ }^{8,9}$ However, despite the fact that many studies have focused on investigation of the correlation between various deposition parameters and the resulting properties of $(\mathrm{Ti}, \mathrm{Al}) \mathrm{N}$ thin films, see, e.g., Refs. 10 and 11, the correlation between cathode composition, plasma generation, plasma properties, and film synthesis is comparatively unexplored. Bilek et $a l .{ }^{12}$ described plasma composition, ion charge states, and ion energy distributions (IEDs) for filtered pulsed arc plasma generated from compound $\mathrm{Ti}-\mathrm{Al}$ cathodes. However, no

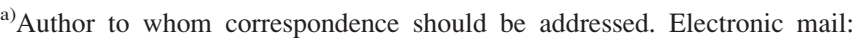
igozh@ifm.liu.se, Telephone: +46730521012, Fax: +4613137568
}

similar study has been reported for unfiltered DC arc plasma, a technique more commonly applied in industrial settings. ${ }^{13,14}$ To increase the fundamental understanding of the deposition process, and, in turn, enable an improved control of the coating properties, highly motivates such studies. Recent reports in literature contribute to an emerging description of arc plasma generation from compound cathodes, where a dependences of plasma properties on cathode elemental as well as phase composition is indicated. ${ }^{12,15-18}$

Here, we investigate the influence of Ti-Al cathode composition on cathode, plasma, and basic film properties, for dc vacuum arc. The absence of working gas as well as macroparticle filter allows us to exclude known effects of gas and magnetic field on the plasma properties, ${ }^{19,20}$ and to provide a base for fundamental understanding of arc plasma generation from Ti-Al compound cathodes.

\section{EXPERIMENTAL DETAILS}

\section{A. Plasma analysis}

The experiments were performed using a deposition system equipped with an industrial scale DC arc source (Ionbond) for $63 \mathrm{~mm}$ diameter cathodes. $\mathrm{Ti}, \mathrm{Al}$, and $\mathrm{Ti}_{1-\mathrm{x}} \mathrm{Al}_{\mathrm{x}}$ 
$(\mathrm{x}=0.16,0.25,0.50$, and 0.70$)$ cathodes were used, as produced by powder metallurgy. ${ }^{21}$ The cathodes were used for at least $10 \mathrm{~min}$ prior to any measurements, to remove eventual surface contaminants and achieve steady state conditions. The arc source was operated at $65 \mathrm{~A}$ arc current at a base pressure around $10^{-6}$ Torr. A mass-energy-analyzer (MEA, Hiden Analytics model EQP) was placed in front of the arc source with the orifice ( $50 \mu \mathrm{m}$ diameter) about $33 \mathrm{~cm}$ from the cathode surface. For each cathode, the plasma was characterized through mass-scans at fixed ion energy and energy-scans at fixed mass-to-charge ratio for all ions of $\mathrm{Ti}$ and $\mathrm{Al}$. The energy scans were recorded in steps of $0.25 \mathrm{eV} /$ charge up to $200 \mathrm{eV} /$ charge to capture the entire IED. Each IED was recorded at least three times to ensure consistency of the data. Over time, the MEA orifice may be coated and the recorded intensity reduced as an effect of reduced orifice size. This effect was not significant for the set of measurements performed for one cathode, as determined by repeated measurements, which also confirms that steady state conditions were sampled. The scans acquired for a particular cathode can thus readily be compared. To determine the plasma composition, the IEDs were integrated to obtain areas proportional to the number of ions of each species. Integral average energies, $E_{\text {avg }}$, were also calculated according to

$$
E_{\text {avg }}=\frac{\int I \cdot E \cdot d E}{\int I \cdot d E} .
$$

For comparisons between different cathodes, the analysis relies on relative data obtained separately for each cathode. The average ion energies and the ratios between IEDs of different ions were found to be reproducible within 5\%.

\section{Effects of isotope distribution on analysis of plasma composition}

In the present work, the major isotope was measured in all cases, except for $\mathrm{Ti}^{2+}$, where the isotope at $23 \mathrm{amu} / \mathrm{charge}$ (doubly charged ion of the $46 \mathrm{amu}$ isotope) was selected to avoid detector saturation. This could be compensated for numerically in the data analysis using the natural isotope distribution. ${ }^{22}$ If selecting the major isotope of $\mathrm{Ti}$ (48 amu) for evaluation, the experimental analysis would include only $73.8 \%$ of all $\mathrm{Ti}$ ions. Therefore, the intensities should be multiplied by $\sim 1.35$ to receive the number of all Ti ions. However, such correction coefficients can only be used when there is no overlap between the signals of the isotopes, which in turn depends on the mass resolution of the plasma analyzer. The correlation between the natural isotope distribution and the mass resolution of the analyzer has been investigated in the present study by measuring the relative intensity of the singly charged ions of the isotopes between 46 and 50 amu, see Fig. 1(a).

Figure 1(a) verifies the tabulated natural isotope distribution for $\mathrm{Ti}^{1+}$ ions and demonstrates the mass resolution of the analyzer. Evidently, there is overlapping only between the isotope's signals for doubly charged ions, see Fig. 1(b). Comparing the isotope signals from singly (a) and doubly (b) charged ions, the mass resolution of the analyzer can be estimated to $0.9 \mathrm{amu}$, with a signal associated to a specific mass including all ions in the range $\pm 0.45 \mathrm{amu}$. The correction coefficients to be used in case of isotope overlap can be estimated through the ratio between the integral of a signal in the range $\pm 0.45 \mathrm{amu}$, and the integral of the signals from all isotopes in the full isotope mass range. It is known that the mass resolution of a quadruple analyzer depends on the time spent inside the quadruple, ${ }^{23}$ i.e., depends on the ion velocities. However, considering that the ion velocities in an arc discharge do not depend on the ion charge state, ${ }^{24}$ a mass resolution equal to $0.9 \mathrm{amu}$ was used for all $\mathrm{Ti}$ ions. The resulting correction coefficients included in this work are 1.35 for $\mathrm{Ti}^{1+}$ (48 amu), 8.65 for $\mathrm{Ti}^{2+}(23 \mathrm{amu})$, and 1.2 for $\mathrm{Ti}^{3+}$ (16 amu). A comparison of plasma composition and average charge state, estimated from the natural isotopes distribution and from the above determined correction coefficients, is discussed in Secs. IIIA 2 and III A 3. The Ti average ion energies were found to be close to independent on correction coefficients. Corresponding analysis for $\mathrm{Al}$ ions is not motivated, since Al has only one stable isotope $(27 \mathrm{amu}) .^{22}$

\section{B. Film growth}

Films were deposited from the $\mathrm{Ti}_{0.5} \mathrm{Al}_{0.5}$ and the $\mathrm{Ti}_{0.3} \mathrm{Al}_{0.7}$ cathodes by fixing a $\mathrm{Si}(100)$ substrate in a position equivalent to the front end of the plasma analyzer, at grounded potential. Temperature calibration showed a substrate temperature not exceeding $250^{\circ} \mathrm{C}$.
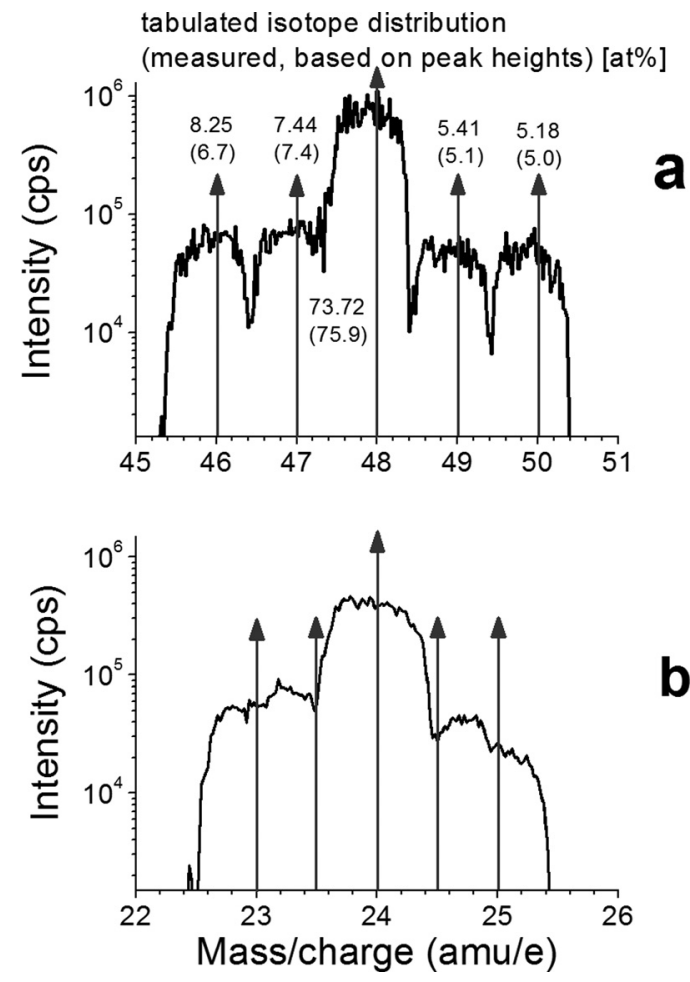

FIG. 1. Isotope distribution of singly (a) and doubly (b) charged Ti ions (from a Ti cathode, used at base pressure). 


\section{Structural and compositional materials analysis}

The phase structures of the cathodes were examined by X-ray diffractometry (XRD) using a PANalytical X'PERT $\mathrm{X}$-ray diffractometer with a line-focus $\mathrm{Cu} \mathrm{K} \alpha \mathrm{X}$-ray source, where $\theta-2 \theta$ scans were recorded in the $2 \theta$-range from $25^{\circ}$ to $140^{\circ}$. Compositions of films and cathodes were characterized using a LEO 1550 scanning electron microscope (SEM) equipped for energy dispersive X-ray spectroscopy (EDS).

\section{Calculation details}

The cohesive energy $\mathrm{E}_{\text {cohesive }}$ of a solid phase represents the energy required to break the solid $\left(\mathrm{E}_{\text {solid }}\right)$ into isolated atomic species $\left(E_{\text {isolated }}^{A}\right)$ according to

$$
E_{\text {cohesive }}=\sum_{A} E_{\text {isolated }}^{A}-E_{\text {solid }},
$$

where $A$ represents the different atoms of the solid phase. The calculations of cohesive energies for $\mathrm{Ti}-\mathrm{Al}$ phases were based on density-functional theory within the generalized gradient approximation $(\mathrm{GGA})^{25}$ using the projector augmented wave $(\mathrm{PAW})^{26}$ method implemented in VASP. ${ }^{27,28}$ For solid phases, integration of the Brillouin zone was performed using a Monkhorst-Pack scheme ${ }^{29}$ with a k-point chosen to achieve a convergence of the total energy of less than $0.2 \mathrm{meV}$ per atom. An energy cutoff of $400 \mathrm{eV}$ was used in the expansion of the plane wave functions. Each phase was optimized with respect to cell volume, $c / a$ ratio, as well as internal parameters. For isolated atomic species, spinpolarized functionals were used with atoms in their groundstate spin configurations. Convergence tests show that an orthorhombic supercell with sides of $\sim 20 \AA$ is sufficient to converge the total energy to less than $0.2 \mathrm{meV} / \mathrm{atom}$.

\section{RESULTS AND DISCUSSION}

\section{A. Plasma characterization}

\section{Effect of cathode composition on ion energy}

$\mathrm{Ti}$ and $\mathrm{Al}$ ions of charge states $1+, 2+$, and $3+$ were detected in the plasma from all $\mathrm{Ti}, \mathrm{Al}$, and $\mathrm{Ti}-\mathrm{Al}$ cathodes. No significant intensity was recorded for charge states of $4+$ and higher, as expected for DC arc mode. ${ }^{14}$ Figure 2 exemplifies IEDs as obtained from the $\mathrm{Al}, \mathrm{Ti}$, and $\mathrm{Ti}_{0.5} \mathrm{Al}_{0.5}$ cathodes. The IEDs from the elemental cathodes demonstrate a high-energy tail extending up to $150 \mathrm{eV}$, while the IEDs obtained from the $\mathrm{Ti}_{0.5} \mathrm{Al}_{0.5}$ cathode is narrower (up to $100 \mathrm{eV}$ ) and more symmetrical. Using shifted Maxwellian distributions in line with previous work ${ }^{12,19}$ to describe the here obtained IEDs, it can be noted that the discovered symmetries and loss of high-energy tail corresponds to lower electron temperature in the shifted Maxwellian distributions. The reduced high-energy tail has implications for film synthesis, as energetic ions can serve both to sputter the surface layer of the deposited film, as well as to be implanted and cause defect formation and potential nucleation site for grain growth. Furthermore, ion bombardment during film growth can improve intermixing of the surface near layer and result in densification of the films. ${ }^{30}$
Integrating the IEDs show that the total number of ion counts increases with the addition of $\mathrm{Al}$ in the cathode (for $\mathrm{Ti}-0.94 \times 10^{7}$; for $\mathrm{Ti}_{0.5} \mathrm{Al}_{0.5}-1.73 \times 10^{7}$; for $\mathrm{Ti}_{0.3} \mathrm{Al}_{0.7}-$ $1.92 \times 10^{7}$; and for $\mathrm{Al}-2.12 \times 10^{7}$ ), which is consistent with previous observations for filtered arc plasma. ${ }^{12}$ The EQP used in the present work measures the current from the electron multiplier, which is proportional to the number of ions registered and independent on their charge state. ${ }^{31}$ Therefore, a change in the total ion count reflects a variation of the normalized ion current $\alpha_{\mathrm{i}}$, which is the ratio between the current of the generated ion flux to the full arc current, which was kept constant for the experiments. The normalized ion current from the $\mathrm{Al}$ cathode is higher than for the $\mathrm{Ti}$ cathode $\left(11.2 \%\right.$ and $9.7 \%$, respectively $\left.{ }^{32}\right)$. Furthermore, plasma from a Ti cathode consists of more doubly and triply charged ions than plasma from an $\mathrm{Al}$ cathode. ${ }^{33}$ Therefore, for the same ion flux current, the plasma from the Ti cathodes consists of fewer ions, and it can be concluded that increasing of atomic proportion of $\mathrm{Al}$ in the cathodes increases the efficiency of ion generation through an increased number of generated ions. A alternative explanation is that the increased ion intensity could be explained by a variation in intensity of the ion-to neutral charge-exchange processes. However, as presented in Sec. III A2, there is close to insignificant dependence of the average ion charge states on the $\mathrm{Al}$ content, for both $\mathrm{Al}$ and $\mathrm{Ti}$. Furthermore, the here suggested increase in ion generation efficiency with $\mathrm{Al}$ content is consistent with the previously observed higher erosion rate of $\mathrm{Al}$ cathodes as compared to $\mathrm{Ti}^{34}$

The average ion energies calculated from Eq. (1) is presented in Figure 3(a). The average ion energies from the $\mathrm{Ti}$ cathode $(56 \mathrm{eV})$ and the $\mathrm{Al}$ cathode $(50 \mathrm{eV})$ are comparable with the literature values, see Table I. However, the average $\mathrm{Ti}$ ion energy shows a slight decrease for an $\mathrm{Al}$ concentration up to 50 at. \%, followed by a significant increase up to $61 \mathrm{eV}$ for the $\mathrm{Ti}_{0.3} \mathrm{Al}_{0.7}$ cathode. The average $\mathrm{Al}$ ion energy has an even stronger dependence on cathode composition, and
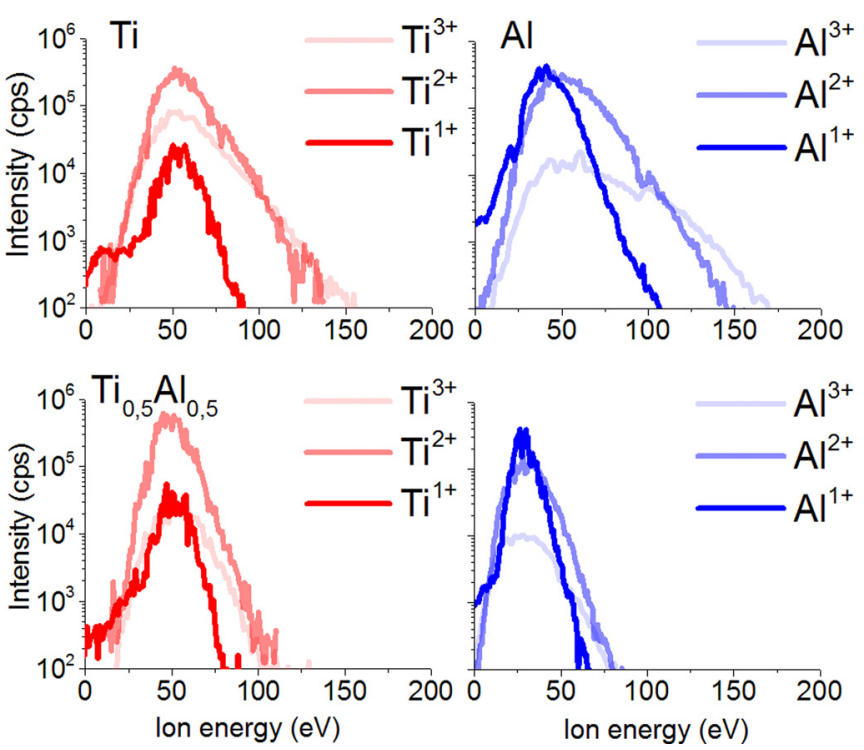

FIG. 2. Ion energy distributions of the plasma from the elemental Ti and Al cathodes and from the $\mathrm{Ti}_{0.5} \mathrm{Al}_{0.5}$ cathode. 

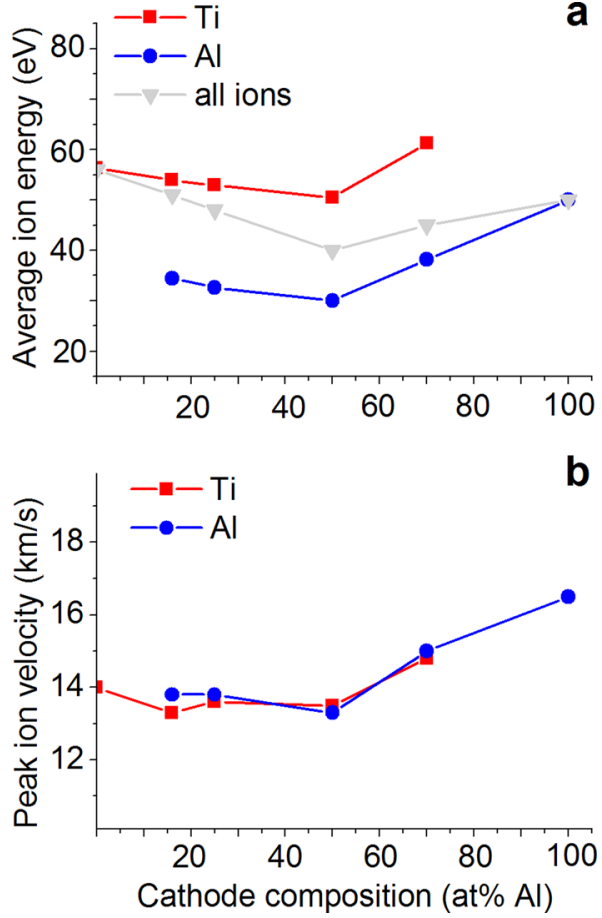

FIG. 3. Average ion energy (a) and peak velocity (b) as a function of the nominal cathode composition.

increases from $\sim 30 \mathrm{eV}$ for the $\mathrm{Ti}_{0.5} \mathrm{Al}_{0.5}$ to $\sim 50 \mathrm{eV}$ for the pure Al cathode. A similar trend has been reported previously by Bilek et al., ${ }^{12}$ through with a more pronounced effect of the addition of $\mathrm{Al}$ to the titanium cathode on the average ion energy. This distinction may be due to the reported presence of a macroparticle filter, previously shown to influence plasma chemistry fluctuations ${ }^{35}$ as well as ion charge states and ion energies. ${ }^{19}$

The ion energy is an important plasma parameter for structural and compositional evolution during film deposition, and the observed increase in average energies with increasing $\mathrm{Al}$ content $(>50$ at. \%) in the cathodes can be explained by similar velocities for ions originating from a compound cathode. Despite ambiguities originating from different plasma analysis techniques, ${ }^{36}$ it is established that the velocity of an ion in the "original" plasma near cathode spots does not depend on the charge state, ${ }^{24}$ due to a gasdynamic mechanism of ion acceleration based on pressure gradients and electron-ion coupling. However, we have

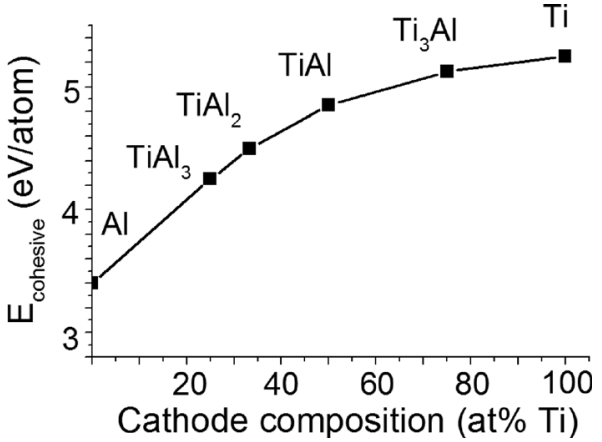

FIG. 4. Calculated cohesive energies of Ti-Al phases.

recently suggested a velocity rule for compound cathodes, ${ }^{16}$ which states that the gas-dynamic mechanism leads to the same peak velocity (most likely velocity, corresponding to the maximum intensity of the ion velocity distribution) also for ions of different mass. The $\mathrm{Al}$ and $\mathrm{Ti}$ ions have similar average ion energies when originating from corresponding elemental cathodes, see Fig. 3(a) and Table I, though with a mass of $27 \mathrm{amu}$ and $48 \mathrm{amu}$, respectively. Through $E=m v^{2} / 2$, this means markedly higher $\mathrm{Al}$ ion velocity as compared to $\mathrm{Ti}$, see the peak velocity for different cathode concentrations in Figure 3(b). For compound cathodes, when the plasma ion velocities is determined mainly by the dominating $\mathrm{Ti}$ component, the $\mathrm{Al}$ ion velocity is reduced as compared to the $\mathrm{Al}$ cathode, due to the similar ion velocities. With an increased addition of $\mathrm{Al}$ in the cathode, the $\mathrm{Al}$ component increase the overall ion velocity, and hence also the ion energy. It should be noted that the slight decrease in average ion energy as $\mathrm{Al}$ is introduced in the Ti cathode, see Figure 3(a), is primarily due to the reduction of high energy tail of the IED, see Figure 2. The IED tail does not influence the peak velocity, and hence there is no corresponding trend observed for the same concentration range in Figure 3(b).

The higher average ion energy for $\mathrm{Ti}$ as compared to $\mathrm{Al}$ in plasma from single element cathodes is consistent with the cohesive energy rule, ${ }^{37}$ a general empirical relationship suggesting higher ion energies for ions originating from higher cohesive energy material. Calculations on cohesive energy of possible phases present in a Ti-Al compound cathode, which shows a monotonically increase when going from pure Al to pure Ti, see Figure 4. Assuming that the cohesive energy rule is valid, this suggests a similar or slightly

TABLE I. Comparison with values of ion charge state and ion energy from Ti and Al elemental vacuum arc taken from the literature.

\begin{tabular}{|c|c|c|c|c|c|c|}
\hline & Method (Ref.) & Average charge & Average energy & $\%$ Singly charged ions & $\%$ Double charged ions & $\%$ Triple charged ions \\
\hline \multirow[t]{5}{*}{$\mathrm{Al}$} & This study & 1.65 & 50 & 42 & 52 & 6 \\
\hline & DC, no filter ${ }^{38}$ & 1.58 & 62 & 49 & 44 & 7 \\
\hline & Pulsed, no filter ${ }^{39}$ & 1.49 & $\ldots$ & 56 & 39 & 5 \\
\hline & Pulsed, no filter ${ }^{40}$ & 1.7 & $\ldots$ & 38 & 51 & 11 \\
\hline & DC, filtered ${ }^{12}$ & 1.89 & 32.7 & 21 & 69 & 10 \\
\hline \multirow[t]{5}{*}{$\mathrm{Ti}$} & This study & 2.2 & 56.4 & 6 & 66 & 28 \\
\hline & Pulsed, no filter ${ }^{39}$ & 2.05 & $\ldots$ & 6 & 82 & 12 \\
\hline & Pulsed, no filter ${ }^{40}$ & 2.03 & $\ldots$ & 11 & 75 & 14 \\
\hline & DC, filtered ${ }^{12}$ & 1.98 & 58.8 & 11 & 80 & 9 \\
\hline & & 2.1 & 55.2 & 8 & 74 & 18 \\
\hline
\end{tabular}


reduced ion energy when introducing $\mathrm{Al}$ in a Ti cathode, and a more significant decrease for more than 50\% Al. However, as $\mathrm{Al}$ becomes the main component in the plasma, such effect is counteracted by the "velocity rule," rent from Figure 3(b). The velocity rule in combination with the much lower mass of $\mathrm{Al}$ compared to $\mathrm{Ti}$, result in overall increasing velocities/energies for a high $\mathrm{Al}$ content, consistent with the findings presented in Figure 3(a).

\section{Effect of cathode composition on ion charge states}

The average ion charge states were calculated from the IEDs and are presented in Figure 5. Applying different correction coefficients based on the tabulated isotope distribution or calculated though the procedure for data evaluation for $\mathrm{Ti}$, as discussed in the experimental section, gives no significant difference in results. The average charge states for $\mathrm{Al}$ and $\mathrm{Ti}$ ions $(\sim 1.65$ and $\sim 2$, respectively) are in agreement with the literature values for elemental cathodes, see Table I, for the here investigated full range of $\mathrm{Al}$ concentrations in the cathodes. This suggests absence of a significant effect of the cathode composition on the average elemental ion charges states. The correlation of the ion charge state distribution (CSD) and the electron temperature for an equilibrium plasma is given by the model of partial local Saha equilibrium (PLSE).$^{41}$ The model implies that the expanding plasma is divided in distinct zones close to the cathode spot, where the ion charge state ratios "freeze" successively, with the largest ionization transition energies first. After the PLSE transition zones, the CSD remains practically constant. This model has been verified for vacuum arc discharges and elemental cathodes, and we suggest that the qualitative picture of a frozen CSD after the transition zones close to the cathode spot is relevant also for compound cathodes. A quantitative prediction of CSD, on the other hand, is based on ionization energies of the individual elements, the electron temperature, and the plasma density, in turn likely affected by the surface state of the cathode, such as phases and impurities present. We therefore consider another rationalization for altered charge states in arc plasma generated from compound cathodes, which has been proposed based on the suggestion that the electron temperature would attain a weighted average of the pure element electron temperatures for the contributing materials. ${ }^{15}$ This has implications for the charge state distribution, where higher ion charge states may form

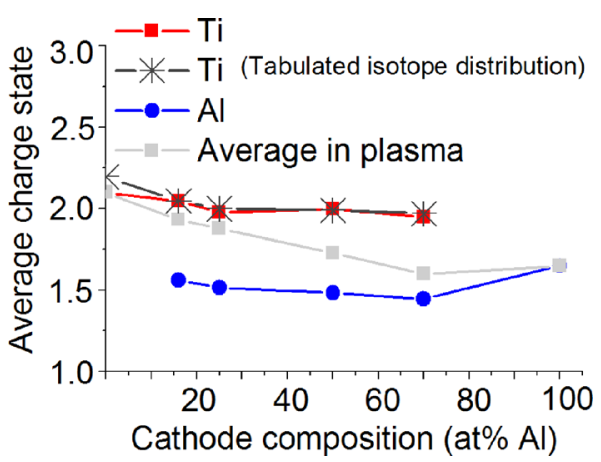

FIG. 5. Average ion charge states as functions of the nominal Ti-Al cathode composition. for the cathode constituent exhibiting lower electron temperature in the pure elemental cathode, while the highest charge states may not form for the high electron temperature component. The electron temperatures for $\mathrm{Ti}$ and $\mathrm{Al}$ in pure form are 3.2 and $3.1 \mathrm{eV}$, respectively. ${ }^{33}$ Therefore, no significant difference from the reference data for the pure elements can be expected, as shown in Fig. 5. However, the overall average ion charge state is decreasing with the addition of $\mathrm{Al}$ into the cathode, which should be considered in film depositions utilizing a biased substrate.

\section{Effect of cathode composition on plasma composition}

Summarizing the integrated areas of the IEDs for all $\mathrm{Ti}$ and $\mathrm{Al}$ ions and applying the correction coefficients for $\mathrm{Ti}$ ions as presented above, allows determination of the plasma composition, see Figure 6. As seen, the $\mathrm{Al}$ ion content diverges from the nominal cathode composition with around $\sim 5 \%$, which is an effect even more pronounced when simply using the tabulated isotope distribution without correction coefficients. General features of plasma generation from compound cathodes could be responsible for this shift. It is known that in plasma generation from compound cathodes, different angular distribution of different cathodic elements is possible, ${ }^{42}$ which could possibly be the case also for Ti-Al. It should be noted that a shift in $\mathrm{Al}$ concentration of 5\% is close to the accuracy of the plasma analyzer, also after use of here estimated correction coefficients. Mass discrimination effect, ${ }^{43,44}$ which depends on a difference between mas$\mathrm{s} / \mathrm{charge}$ of different ions, can influence the results. However, to investigate the correlation between plasma composition and cathode composition further, not only the angular ion distribution but also the cathodes need to be characterized.

\section{B. Cathode characterization}

The elements are unevenly distributed in the as-received (virgin) cathodes as shown by EDS results presented in Table II. Ti ( Ti K $\alpha 1)$ and $\mathrm{Al}(\mathrm{Al} \mathrm{K} \alpha 1)$ are represented by the light areas in respective row. A more homogeneous distribution of the elements on the Ti-Al surfaces of the used Ti-Al compound cathodes suggests element mixing by the arc discharge. Obviously, cathode erosion by arc spot movement

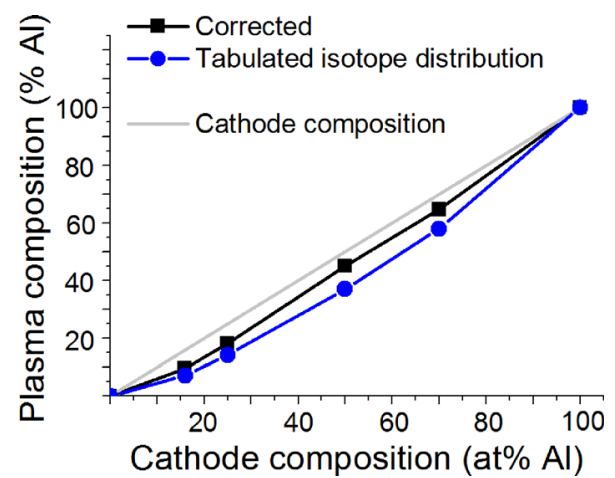

FIG. 6. Plasma composition as a function of the nominal Ti-Al cathode composition. 
TABLE II. SEM and EDS images of the cathodes before and after plasma generation.

\begin{tabular}{|c|c|c|c|c|}
\hline \multirow{2}{*}{$\begin{array}{l}\text { Nominal cathode } \\
\text { composition }\end{array}$} & \multicolumn{2}{|c|}{$\mathrm{Ti}_{0.5} \mathrm{Al}_{0.5}$} & \multicolumn{2}{|c|}{$\mathrm{Ti}_{0.3} \mathrm{Al}_{0.7}$} \\
\hline & virgin & Used & virgin & used \\
\hline \multicolumn{5}{|c|}{$\operatorname{SEM}(1 \mathrm{~mm} \times 0.75 \mathrm{~mm})$} \\
\hline \multicolumn{5}{|c|}{ EDS Ti K $\alpha 1(1 \mathrm{~mm} \times 0.75 \mathrm{~mm})$} \\
\hline \multicolumn{5}{|c|}{$\operatorname{EDS~Al~K\alpha 1}(1 \mathrm{~mm} \times 0.75 \mathrm{~mm})$} \\
\hline EDS composition & $\mathrm{i}_{0.34} \mathrm{Al}_{0 .}$ & $\mathrm{Ti}_{0.46} \mathrm{Al}_{0}$ & $\mathrm{i}_{0.18} \mathrm{Al}_{0 .}$ & $0.32 \mathrm{Al}_{\mathrm{C}}$ \\
\hline
\end{tabular}

involving transformation from solid to liquid and plasma would promote such mixing.

The Al content, measured on the cathode surface before arc plasma generation, is higher than the nominal cathode composition for both the $\mathrm{Ti}_{0.5} \mathrm{Al}_{0.5}$ and the $\mathrm{Ti}_{0.3} \mathrm{Al}_{0.7}$ cathode. This could be due to inhomogeneities on lateral and/or depth scale. However, the EDS results for the used cathodes demonstrate good agreement with the nominal cathode composition, likely due to improved element mixing and, due to that, an improved homogeneity.

The presence of intermetallic compounds in a cathode can potentially change average ion charge states as well as average ion energies. The as-received cathodes consist of a mixture of pure elements $\mathrm{Ti}$ and $\mathrm{Al}$ as determined by XRD, see Fig. 7, with no major change in phase composition with increasing $\mathrm{Al}$ concentration.

Obviously, the treatment of the cathode surface by the arc spot, which has a temperature of a few thousands degrees, ${ }^{45}$ can change the phase composition of the cathode surface layer. $^{46}$ The used cathodes, see top part of Fig. 7, show peaks of $\mathrm{Ti}$ and $\mathrm{Al}$ as well as $\mathrm{Ti}_{3} \mathrm{Al}$. There is a decrease in Ti peak intensity with decreasing Ti content, accompanied by an increase in the $\mathrm{Ti}_{3} \mathrm{Al}$ intensity. However, increasing the $\mathrm{Al}$ content from 50 to 70 at. $\%$, the $\mathrm{Ti}_{3} \mathrm{Al}$ peaks are drastically reduced, in favour of a peak at $2 \theta=43^{\circ}$, which cannot be unambiguously identified. Several Ti-Al phases are however found to have high intensity peaks at that position. A combination of such phases and possible solid solutions between them is very difficult to resolve. The above presented XRD and energy dispersive $x$ ray (EDX) analysis of as-received and used cathodes implies that the initial state of the cathode (grain size, inhomogeneities, defects) is of less importance, as the plasma generation change the cathode surface layer.
The empirical cohesive energy rule, which has established a positive correlation between the cohesive energy of the cathode material and the ion charge states, ${ }^{35}$ was recently suggested to be applicable not only for elemental cathodes but also for intermetallic compounds. ${ }^{17}$ For Ti-Al intermetallic compounds, all cohesive energies are in between the cohesive energies of $\mathrm{Ti}$ and $\mathrm{Al}$, with a range of $\sim 1.5 \mathrm{eV}$, see Fig. 4. The cohesive energy of the $\mathrm{Ti}_{3} \mathrm{Al}$ compound is only $0.25 \mathrm{eV}$ lower than the energy for pure Ti. This suggest that any changes in plasma generation from the compound $\mathrm{Ti}-\mathrm{Al}$ cathode indicated by the cohesive energy rule would be only minor due to insignificant variation of the cohesive energies of the cathode components.

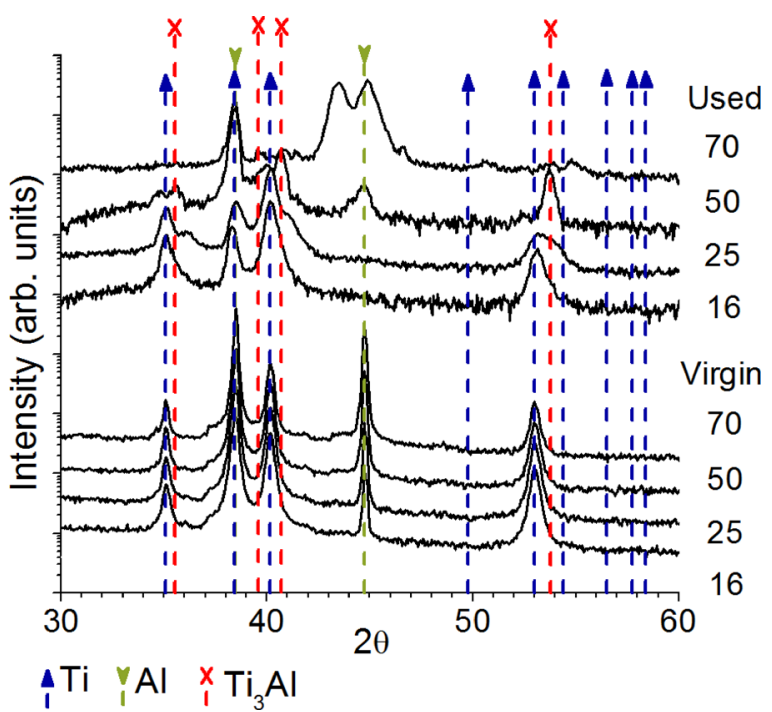

FIG. 7. XRD pattern from the as-received and used Ti-Al cathodes. The numbers to the right correspond to at. $\% \mathrm{Al}$ in the cathodes. 
TABLE III. Cathode, plasma (ions), and film composition.

\begin{tabular}{lll}
\hline \hline Nominal cathode composition (at. \%) & $\mathrm{Ti}_{0.5} \mathrm{Al}_{0.5}$ & $\mathrm{Ti}_{0.3} \mathrm{Al}_{0.7}$ \\
Plasma ion composition (at. \%) & $\mathrm{Ti}_{0.55} \mathrm{Al}_{0.45}$ & $\mathrm{Ti}_{0.35} \mathrm{Al}_{0.65}$ \\
Film composition from EDS (at. \%) & $\mathrm{Ti}_{0.48} \mathrm{Al}_{0.52}$ & $\mathrm{Ti}_{0.28} \mathrm{Al}_{0.72}$ \\
\hline \hline
\end{tabular}

\section{Thin film characterization}

To investigate any discrepancy between cathodeplasma-film element ratio, thin films were grown using the $\mathrm{Ti}_{0.5} \mathrm{Al}_{0.5}$ or the $\mathrm{Ti}_{0.3} \mathrm{Al}_{0.7}$ cathodes. The $\mathrm{Al} / \mathrm{Ti}$ ratio in the films, as determined by EDS, were in good agreement with the cathode compositions, see Table III.

The results show that despite the 5\% discrepancy between cathode and plasma composition, there is only a slight discrepancy between the element ratio in the cathode and the deposited films. This may, at least in part, be explained by the presence of neutrals. One of the special features of DC arc plasma is a significant number of neutral atoms. ${ }^{14}$ These atoms are not registered in the plasma analyzer mode used for the present investigation, but they are incorporated in the film. Neutrals can be generated from mechanisms such as evaporation from previously active arc spots on the cathode surface, ${ }^{47}$ evaporation from macro particles, ${ }^{48}$ and resputtering from previously deposited layers. ${ }^{49}$ Also, $\mathrm{Al}$ has higher vapor pressure and lower boiling temperature than $\mathrm{Ti}^{50},{ }^{50}$ which may suggest a disproportion of the elemental ratio in the neutral vapor, which in turn may eliminate the slight discrepancy in plasma composition as compared to cathode and film composition. It has also been shown that resputtering from previously deposited layers is more pronounced for lighter elements, ${ }^{51}$ so the disproportion in the vapor phase could be even bigger than in plasma phase. However, the close agreement between cathode, plasma, and film composition in the present study allow us to conclude that neutral vapor is a minor contribution to the actual film growth. To further clarify mechanisms behind and presence of neutrals, further experiments are needed, specifically focused on neutrals from a DC unfiltered arc source.

XRD analysis of the deposited films, shown in Fig. 8, demonstrates only minor amounts of intermetallic Ti-Al

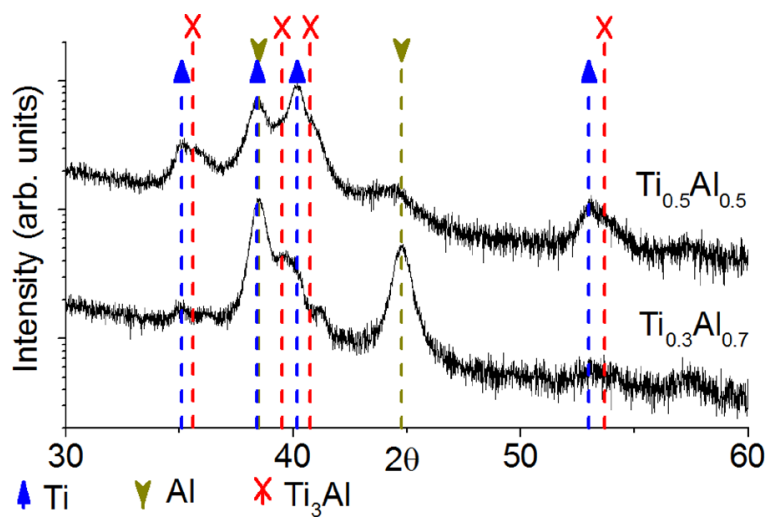

FIG. 8. XRD pattern from the deposited films; the legend on the right side denotes the cathodes used.
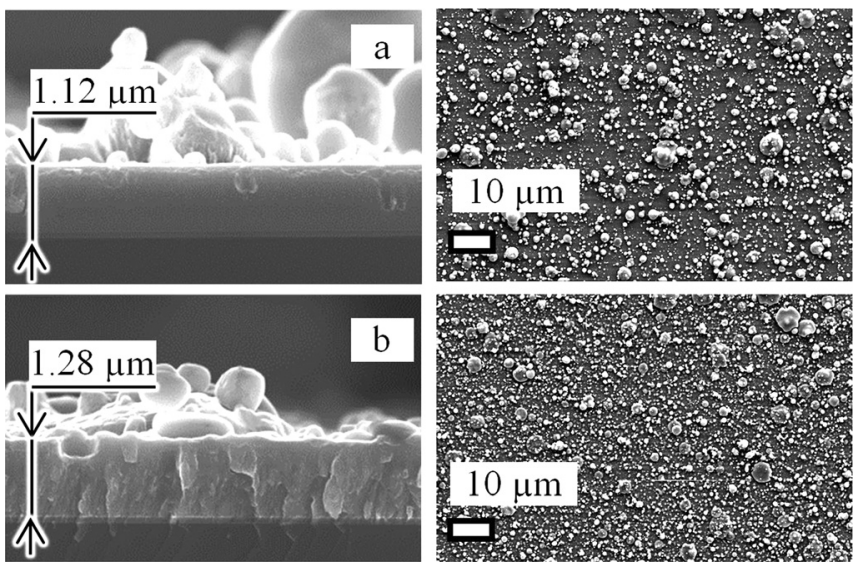

FIG. 9. SEM images of the surface (left) and thickness (right) of the films deposited with plasma from $\mathrm{Ti}_{0.5} \mathrm{Al}_{0.5}$ (a) and $\mathrm{Ti}_{0.3} \mathrm{Al}_{0.7}$ (b) cathodes.

compounds. The deposited films consist essentially of a mixture of single element phases, which may be explained by the low deposition temperature $\left(\leq 250^{\circ} \mathrm{C}\right)$ and grounded substrate potential during deposition.

Figure 9 demonstrates an increase in film thickness with an increased $\mathrm{Al}$ content in the cathode. The presented values are averages from 5 measurements in different positions, with a variation below $7 \%$. This is consistent with the observed increase in plasma ion intensity $\mathrm{Ti}_{0.5} \mathrm{Al}_{0.5}-1.73 \times 10^{7}$ and $\mathrm{Ti}_{0.3} \mathrm{Al}_{0.7}-1.92 \times 10^{7}$, see Sec. III A 1 However, even though the thickness was measured in locations free from macroparticles on the surface, excluding the contribution of macroparticles to the film thickness is not possible. ${ }^{14}$ It should also be noted that there is an increased number of macroparticles with increased $\mathrm{Al}$ content in the cathode. This may be understood in light of studies on elemental cathodes, where an increased abundance of macroparticles has been observed for lower melting point materials. ${ }^{52,53}$ However, a monotonic relationship between the number of macroparticles and the melting temperature could not been established, suggesting that macroparticle production, in particular from compound cathodes, is more complex than just a function of one material parameter. ${ }^{17,52}$

\section{CONCLUSION}

Vacuum arc plasma from Ti-Al compound cathodes has been characterized with respect to ion composition, ion charge state, and ion energy. The proportion of $\mathrm{Al}$ in the ionic part of the plasma is approximately 5 at. \% lower than the corresponding cathode content, while composition of concurrently grown films agrees well with the cathode composition. This could imply presence of neutrals. Furthermore, the total number of generated ions was found to be growing with the addition of $\mathrm{Al}$ in the cathode compound, which scales with an increase in film thickness. That effect could be explained by increased current efficiency of the arc discharge on a cathode with a higher amount of Al. The average ion charge states of the elements were approximately independent of the cathode composition, while the width of the energy distributions were drastically reduced when going from elemental to compound cathodes, going from $\sim 150$ and $\sim 175 \mathrm{eV}$ to $\sim 100$ and 
$\sim 75 \mathrm{eV}$ for $\mathrm{Ti}$ and $\mathrm{Al}$ ions, respectively. This may be explained by a reduction in electron temperature, commonly associated with the high energy tail of the IED. The average ion energies ranged between $30 \mathrm{eV}$ and $61.5 \mathrm{eV}$, depending on the cathode composition, and with trends consistent with the velocity rule for compound cathodes. Furthermore, element mixing in the cathode by the arc discharge was demonstrated through EDX and XRD analysis of the as-received and used cathodes, also showing formation of the intermetallic $\mathrm{Ti}_{3} \mathrm{Al}$ compound. This implies that the cathode composition is one of the primary parameters influencing the plasma generation, and that small scale inhomogeneities and defects may be of less importance. The presented findings are of importance for the fundamental understanding of film synthesis involving compound cathodes, as plasma generation, ion charge states, and ion energies affect both compositional and structural evolution of the thin film, especially when utilizing a substrate bias.

\section{ACKNOWLEDGMENTS}

This work was funded by the European Research Council under the European Community's Seventh Framework Programme (FP7/2007-2013)/ERC Grant agreement No. 258509. J.R. acknowledges funding from the Swedish Research Council (VR) Grant No. 642-2013-8020 and from the KAW Fellowship program. Calculations of the cohesive energies were performed utilizing supercomputer resources provided by the Swedish Infrastructure for Computing (SNIC) at the NSC center.

${ }^{1}$ D. Mclntyre, J. Greene, G. Hakansson, E. Sundgren, and W. Munz, J. Appl. Phys. 67(3), 1542-1553 (1990).

${ }^{2}$ C. Jarm, H. Stock, and P. Mayr, Surf. Coat. Technol. 108/109, 206-210 (1998).

${ }^{3}$ W. Münz, J. Vac. Sci. Technol. A 4(6), 2717-2725 (1986).

${ }^{4}$ S. Danisman, S. Savas, and E. Topal, Tribol. Industry 30(1/2), 17-22 (2008).

${ }^{5}$ H. Barshilia, M. Prakash, A. Jain, and K. Rajam, Vacuum 77(2), 169-179 (2005).

${ }^{6} \mathrm{~J}$. Hermann, S. Hofmann, and W. Munz, Thin Solid Films 153, 45-53 (1987). ${ }^{7}$ F. Weber, F. Fontaine, M. Sheib, and W. Bock, Surf. Coat. Technol. 177-178, 227-232 (2004).

${ }^{8}$ S. PalDey and S. Deevi, Mater. Sci. Eng. A 342, 58-79 (2003).

${ }^{9}$ A. Hörling, L. Hultman, M. Odén, J. Sjölén, and L. Karlsson, "Thermal stability of arc evaporated high aluminum-content $\mathrm{Ti}_{1_{-x}} \mathrm{Al}_{\mathrm{x}} \mathrm{N}$ thin films," J. Vac. Sci. Technol. 20, 1815-1823 (2002).

${ }^{10}$ Y. Chang, D. Wang, and C. Hung, Surf. Coat. Technol. 200, 1702-1708 (2005).

${ }^{11}$ M. Li and F. Wang, Surf. Coat. Technol. 167, 197-202 (2003).

${ }^{12}$ M. M. M. Bilek, P. J. Martin, and D. R. McKenzie, J. Appl. Phys. 83(6), 2965-2970 (1998).

${ }^{13}$ B. Coll and M. Chhowalla, Surf. Coat. Technol. 68/69, 131-140 (1994).

${ }^{14}$ A. Anders, "Cathodic arcs," in From Fractal Spots to Energetic Condensation, 1st ed. (Springer, New York, 2008).

${ }^{15}$ K. Savkin, Y. Yushkov, A. Nikolaev, E. Oks, and G. Yushkov, Rev. Sci. Instrum. 81(2), 02A501-1-02A501-3 (2010).

${ }^{16}$ I. Zhirkov, A. Eriksson, and J. Rosen, "Ion velocities in direct current arc plasma generated from compound cathodes," J. Appl. Phys. 114, 2133021-213302-4 (2013).

${ }^{17}$ A. Eriksson, I. Zhirkov, M. Dahlqvist, J. Jensen, L. Hultman, and J. Rosen, J. Appl. Phys. 113(16), 163304-1-163304-7 (2013).
${ }^{18}$ J. Sasaki and I. Brown, J. Appl. Phys. 66, 5198-5203 (1989).

${ }^{19}$ J. Rosén, A. Anders, S. Mráz, and J. Schneider, "Charge-state-resolved ion energy distributions of aluminum vacuum arcs in the absence and presence of a magnetic field," J. Appl. Phys. 97, 103306 (2005).

${ }^{20}$ J. Rosén, A. Anders, S. Mráz, A. Atiser, and S. Jochen, "Influence of argon and oxygen on charge-state-resolved ion energy distributions of filtered aluminum arcs," J. Appl. Phys. 99, 123303 (2006).

${ }^{21}$ G. Korb, "Process for the Manufacture of a target for cathodic sputtering," Patent US 4752335 (1987).

${ }^{22}$ CRC Handbook of Chemistry and Physics ed. 92, Internet Version, 2012.

${ }^{23} \mathrm{~V}$. Titov, "Ion separation in imperfect fields of the quadrupole mass analyser Part III. Transmission and optimal ion injection," Int. J. Mass Spectrometry Ion Process. 141, 37-43 (1995).

${ }^{24} \mathrm{~A}$. Anders and E. Oks, "Charge-state-resolved ion energy distribution functions of cathodic vacuum arcs: A study involving the plasma potential and biased plasmas," J. Appl. Phys. 101, 043304 (2007).

${ }^{25}$ J. Perdew, K. Burke, and M. Ernzerhof, Phys. Rev. Lett. 77, 3865-3868 (1996).

${ }^{26}$ P. Blöchl, Phys. Rev. B 50, 17953-17979 (1994).

${ }^{27}$ G. Kresse and J. Hafner, Phys. Rev. B 48, 13115-13118 (1993).

${ }^{28}$ G. Kresse and J. Hafner, Phys. Rev. B 49, 14251-14269 (1994).

${ }^{29}$ H. Monkhorst and J. Pack, Phys. Rev. B 13, 5188-5192 (1976).

${ }^{30} \mathrm{~K}$. Müller. "Ion-beam-induced epitaxial vapor-phase growth: A moleculardynamics study,” Phys. Rev. B 35, 7906-7913 (1987).

${ }^{31}$ Hiden Analytical Limited, "EQP/EQS Analyser Operator's Manual," no. F Revision 1, 2009.

${ }^{32}$ A. Anders, E. Oks, G. Yushkov, K. Savkin, I. Brown, and A. Nikolaev, IEEE Trans. Plasma Sci. 33, 1532-1536 (2005).

${ }^{33} \mathrm{~A}$. Andre, "Ion charge state distributions of vacuum arc plasmas: The origin of species,” Phys. Rev. E 55, 969-981 (1997).

${ }^{34} \mathrm{~S}$. Anders and B. Juttner, "Influence of residual gases on cathode spot behavior," IEEE Trans. Plasma Sci. 19(5), 705-712 (1991).

${ }^{35}$ J. Rosen, A. Anders, and J. M. Schneider, "Plasma chemistry fluctuations in a reactive arc plasma in the presence of magnetic fields," Appl. Phys. Lett. 80(22), 4109-4111 (2002).

${ }^{36}$ J. Rosén, J. Schneider, and A. Anders, "Charge state dependence of cathodic vacuum arc ion energy and velocity distributions," Appl. Phys. Lett. 89, 141502 (2006).

${ }^{37} \mathrm{~A}$. Anders, "The evolution of ion charge states in cathodic vacuum arc plasmas: A review," Plasma Sources Sci. Technol. 21, 035014 (2012).

${ }^{38}$ W. Davis and H. Miller, J. Appl. Phys. 40, 2212-2221 (1969).

${ }^{39}$ I. Brown, B. Feinberg, and J. Galvin, J. Appl. Phys. 63, 4889-4898 (1988).

${ }^{40}$ I. Brown, Rev. Sci. Instrum. 65, 3061-3081 (1994).

${ }^{41}$ A. Anders, IEEE Trans. Plasma Sci. 27, 1060 (1999).

${ }^{42}$ A. Nikolaev, G. Yushkov, K. Savkin, and E. Oks, "Angular distribution of ions in a vacuum arc plasma with single-element and composite cathodes," IEEE Trans. Plasma Sci. 41(8), 1923-1928 (2013).

${ }^{43}$ K. Heumann, S. Gallus, G. Radlinger, and J. Vogl, J. Anal. At. Spectrometry 13, 1001-1008 (1998).

${ }^{44}$ L. Wojcik and K. Bederski, "Determination of the ion transmission coefficient for a mass spectrometer with a quadrupole ion analyzer," Int. J. Mass Spectrometry Ion Process. 153, 139-144 (1996).

${ }^{45} \mathrm{~T}$. Utsumi, "Measurements of cathode spot temperature in vacuum arcs," Appl. Phys. Lett. 18, 218-220 (1971).

${ }^{46}$ D. Rafaja, C. Polzer, G. Schreiber, P. Polcik, and M. Kathrein, "Surface modification of Ti-Al targets during cathodic arc evaporation," Surf. Coat. Technol. 205(21-22), 5116-5123 (2011).

${ }^{47}$ A. Anders, E. Oks, and G. Yushkov, "Production of neutrals and their effects on the ion charge states in cathodic vacuum arc plasmas," J. Appl. Phys. 102, 043303-1-043303-7 (2007).

${ }^{48}$ G. Lins, IEEE Trans. Plasma Sci. 15, 552-556 (1987).

${ }^{49} \mathrm{~A}$. Anders, "Observation of self-sputtering in energetic condensation of metal ions," Appl. Phys. Lett. 85, 6137-6139 (2004).

${ }^{50}$ R. Honig and D. Kramer, RCA Rev. 30, 285-305 (1969).

${ }^{51}$ A. Eriksson, J. Zhu, N. Ghafoor, M. Johansson, J. Sjölén, J. Jensen, M. Odén, L. Hultman, and J. Rosén, Surf. Coat. Technol. 205, 3923-3930 (2011).

${ }^{52}$ S. Anders, A. Anders, Y. Kin Man, X. Yao, and I. Brown, IEEE Trans. Plasma Sci. 21, 440-446 (1993).

${ }^{53}$ J. Daalder, J. Phys. D: Appl. Phys. 9, 2379-2395 (1976). 